\title{
Best practices for psychological support of communities after a disaster
}

\author{
B. Selzler \& D. Grandbois \\ University of North Dakota, North Dakota State University, USA
}

\begin{abstract}
Historically, the U.S. emergency response system has not provided psychological support to communities impacted by disaster. Instead, the traditional emergency response community focused on preparing for and ensuring the physical survival and safety of the individuals and communities that it protects. However, since the terrorist attacks of September 11, 2001, private and public agencies have enhanced the capacity to respond to the behavioral health impact of disasters both on the community and individual. The goal of all disaster intervention, whether physical or psychological in nature, is to restore the individual to his/her level of pre-disaster functioning. The purpose of this paper is to identify the best practices and evidence-based strategies used to restore communities to pre-existing disaster functional status. A review of the important insights gleaned from U.S. terrorist attacks and from post-Katrina findings reveal many states' practices are limited to providing clinical services or psychological debriefing designed to directly mitigate or lessen the severity of the psychological impact on victims, responders, and nearby community members. Little attention has been paid to the broader psychological, social, functional, and behavioral issues that can impair recovery efforts for both individuals and the communities in which they reside. Helping communities become resilient and recover from devastation in a timely manner will improve the health of communities and decrease economic losses due to lost work time, health care visits, and use of substances to cope.

Keywords: disaster, behavioral health, mental health, resilient communities.
\end{abstract}




\section{Introduction}

Effective psychological support planning for disasters requires that planners have a working knowledge about the range of reactions that are likely to be encountered among survivors, responders, and other helpers. For example, what community groups may be especially vulnerable to negative mental health consequences and what interventions are best, given the nature of the event and the population affected. The need to coordinate the delivery of planned responses across various systems of care and the wide array of community organizations and agencies require broad-based collaborations and solid understanding of best practices with respect to healthy partnership formation and maintenance. Research has identified a range of behavioral responses that people, and communities may have to traumatic events.

Most individuals who experience a catastrophic event do not develop diagnosable psychiatric illness, but the majority report experiences such as sleep disturbance, loss of concentration, or feeling emotionally upset afterward (Norris et al. [1]).

Exposure to a traumatic event affects people in different ways, from feeling mildly upset to having diagnosable behavioral and psychiatric symptoms. Those falling in the latter category most commonly show increased rates of acute stress disorder, posttraumatic stress disorder (PTSD), major depression, panic disorder, generalized anxiety disorder, and substance use disorder (Kaniasty and Norris [2]). Other symptoms associated with exposure to trauma or terror include: impairment of the immune system; non-clinical depression and anxiety; detrimental changes in eating patterns and other, subsequent ill health effects (e.g., stomach pain, intestinal problems, too little or too much sleep, ongoing fatigue). Individuals often have increased levels of risk-seeking behavior (e.g., increased alcohol or substance abuse) coupled with abandonment of usual caretaking behaviors (e.g., increased sexual activities with multiple partners, engaging in risky, unprotected sex acts). Emergency workers, people caring for survivors and others vicariously experiencing the trauma of the disasters, but who are not directly exposed, can experience debilitation from symptoms associated with secondary trauma that may persist for years after the event (Marmar et al. [3]).

In comprehensive literature reviews of the mental health effects of natural and human-caused disasters [1,5], researchers found that for natural disasters, symptoms of PTSD tend to resolve within 18 months, although they may last for as long as three years. Among victims of human-caused disasters, reviewers found that PTSD, other anxiety disorders, depression, and somatization tend to persist longer, although the proportion of people with symptoms declines over the years.

Myriad factors influence the likelihood that an individual within the community will develop serious or lasting psychological problems in the wake of disasters. Gender; age; prior experience; ethnicity; culture; socioeconomic status (SES); family structure; problems of children, parents, or spouses; severity of exposure; secondary stressors; predisaster psychiatric history and personality; all appear to play a role [1]. 


\section{Recent research on behavioral health}

Research focused on recent and previous disasters provides important information about effective interventions that will routinely be needed following disasters at local, state, and national levels. These key interventions include:

- Behavioral health triage. Triage of physical injuries, or the sorting and assigning of treatment according to urgency, is a well established practice in medicine. Mental health concerns also should be triaged. Following a large-scale disaster, a range of developmentally and culturally appropriate treatment modes based on varying levels of need, acuity, and intensity are required. During the time it takes to minister to physical needs, a systemic and comprehensive mental health screening program can be implemented. One example of this kind of program is found in the New York response to the $9 / 11$ terrorist attacks that included a program in which Mount Sinai Medical Center conducted physical health screenings in coordination with crisis counselors who provided psychological first aid and screened for more serious mental health disorders.

- Multiple treatment modalities. Treatment should be research-based and include community natural support networks. Some examples of evidence-based interventions include cognitive-behavioral therapy (CBT) e.g., Ruzek et al. [4] eye movement desensitization and reprocessing (EMDR) e.g., Shapiro and Maxfield [5], as well as other therapies. It is crucial to ensure that these are administered by trained and experienced counselors. Damage can be done by well-meaning helpers who are not adequately qualified. One potentially effective approach revolves around the establishment of a pool of qualified therapists in advance or in the immediate aftermath of a disaster. In New York, Dr. Randall Marshall and his team trained 1,500 mental health workers in proven trauma treatments so they could work in their own communities following the 9/11 terrorist attacks. This proved to be an effective model.

- Credential and screen staff. In the chaos of a disaster, many helpers flock to the scene. Communities should define in advance the various roles that will be enacted following an attack or disaster and the criteria for people qualified to fill those roles. Only qualified people trained for a specific disaster should then be allowed to fill that role. This qualification applies to all people working on the front lines: emergency workers, mental health workers, and faith-based counselors. Optimal planning would include advanced training (Butler et al. [6]). In Utah, the state disaster coordinator developed a training series that led to psychological support credentials for professional mental health workers. The wrong mental health treatment can do more damage than no mental health treatment. 


\subsection{Phases of reactions}

Other research documents phase in reactions of individuals and of communities following disasters (i.e., heroic-honeymoon phase; disillusionment phase; retaliatory-blaming phase; and recovery phase). Such information allows behavioral health planners to anticipate the need for the delivery of specific and timely individual and community interventions. For example, in the heroichoneymoon phase, many people need information about the "normal" and expected responses to their trauma experience. In later phases of disaster, as disillusionment and the pain of losses accumulate, education may be needed to redress stigma or retaliatory acts and hate crimes that can emerge [1].

\subsection{Recovery from trauma}

Other significant research has identified interacting factors that may determine both short-term functioning and long-term adaptation to traumatic events for individuals and social groups (i.e., the psychosocial model of disaster) (Korol et al. [7]) with a special focus on reactions that children and adolescents may experience. These factors include (1) characteristics of the stressor (i.e., extent of loss, life threat); (2) cognitive processing of the event (i.e., magical thinking, appraisal); (3) individual characteristics of the child (i.e., age, sex); and (4) characteristics of the environment (i.e., reactions of family members). The psychosocial model proposed by the authors uses a developmental perspective in which the individual's reactions are anticipated. Such studies not only help identify needed individual-level interventions, but also are critical for anticipating and devising interventions that will be needed for wider distribution or targeted for use with certain age groups or subpopulations. For example, targeted outreach may be needed for members of cultural groups that routinely eschew use of public care systems or for use with groups of people living with predisaster psychiatric disabilities or substance use disorders.

\subsection{Theories of behavioral health}

Public Health theories can inform intervention practices in that a comprehensive working knowledge of the community is needed before disasters occur. Emergency behavioral response planners need to know who is in the community (e.g., enclaves of low-income, disabled, elderly, ethnic or cultural members), the nature of its current infrastructure (e.g., hospitals, clinics, shelters, congregate housing sites, geographic features, transportation, communication mechanisms), the composition of local and state social services and care systems (e.g., workforce, housing, governmental and nongovernmental agencies, and the range of qualified behavioral health responders in the area (e.g., clergy, emergency workers, mental health workers). In short, a comprehensive community assessment focused on disaster response is imperative in planning for the future. 


\section{$3 \quad$ Emergency planning}

Emergency planning in this century confronts new realities and needs to incorporate the lessons learned from recent tragic events in the United States. In the national struggle to confront and resolve the mental health issues associated with - and exacerbated by - disasters, the lessons learned during two catastrophes in the United States, the 9/11 terrorist attacks and Hurricane Katrina, are particularly instructive. The aftermath conditions of these disasters exemplify a range of individual reactions and structural issues that need to be anticipated so that effective responses to the complex mental health needs that emerge after disasters can be marshaled.

Terrorist activities in 2001 challenged the United States to learn new ways of responding to devastating crises that would provide a sense of safety and security to the public. A retrospective summary judgment about the nation's lack of preparedness to redress psychological damage associated with terrorist-instigated disasters was noted in a 2003 Institute of Medicine report:

The nation's mental health, public health, medical, and emergency response systems currently are not able to meet the psychological needs that result from terrorism. Gaps exist in the coordination of agencies and services, training and supervision of professionals, public communication and dissemination of information, financing, and knowledge- and evidence-based services Institute of Medicine [8].

\section{Lessons from terrorist attacks}

Following the 9/11 terrorist attacks, the extent of psychological impact became apparent and the need for a well-coordinated public mental health response system to prepare for terrorism was emphasized (ibid).

Numerous studies (Schuster et al. [9], North et.al. [10], Schlenger et al. [11], Silver et al. [12]) have examined the mental health consequences of major terrorist attacks experienced in the United States (i.e., Oklahoma City bombing, the World Trade Center, the Pentagon, and the anthrax attacks in 2002-2003). As a whole, the studies revealed that the effects from acts of terrorism on mental health affected a higher percentage of people and that the effects were more enduring than the negative psychological outcomes reported in previous studies for natural or accidental disaster survivors. Salient findings from some of these studies are highlighted below.

- The Schuster et al. [9] study, conducted three to five days after September 11,2001 , found that 44 percent of the adults surveyed reported one or more substantial symptoms of stress, and 90 percent had one or more 
symptoms. The study also identified a relationship between time spent watching replays of the attacks on television and reported increases in anxiety, sleep disturbance, and generally low or depressed mood.

- Silver et al. [12] found that respondents' use or abandonment of coping strategies in the aftermath of the 9/11 terrorist attacks operated as predictors of long-term distress.

- Cardenas et al. [13] examined the effects of 9/11 terrorist attacks on a Midwestern university population 600 miles from New York City. Two years after the attacks, 76.5 percent of the study participants reported experiencing PTSD criteria of fear, helplessness, and horror four to six months after the event.

- Boscarino et al. [14] investigated the levels of fear of future terrorism in New York one year after September 11, 2001. Approximately half of those surveyed expressed considerable fear of further attacks, including future biological and nuclear attacks.

- Multiple negative mental health effects were found not only for residents directly exposed to the terror attack, but also by those indirectly exposed via disturbing media images (Butler et al. [6], Galea et al. [15], Marshall and Galea [16]). The symptoms of individuals who were indirectly exposed to the attacks via the media can be as intense as those directly exposed. Prolonged, repetitive exposure to the horrific images of terror may contribute to ongoing heightened levels of posttraumatic stress and related mental health problems in the wider society well after the actual attack [12].

\subsection{Lessons from Hurricane Katrina}

Recent findings from studies of the psychological outcomes after Hurricane Katrina in 2005 both underscore and expand the knowledge gained about survivors' psychological distress from 9/11 experiences and the aftermath (e.g., Wang et al. [17], Kessler et al. [18], Galea et al. [15], DeSalvo et al. [19]). Many of these studies stand in contrast to findings from other disaster studies, where post-disaster mental disorders typically decrease with time. Highlights of some of these post-Hurricane Katrina summary findings include:

- Among Hurricane Katrina survivors, PTSD, serious mental illness, suicidal ideation, and suicide plans prevalence increased significantly. Unresolved hurricane-related stressors accounted for large proportions of the increases in the incidence of serious mental illness [18].

- Eighteen months after Hurricane Katrina hit, of those who had used mental health services before the storm, 60 percent had stopped using 
them [17]. Under treatment was greatest among respondents who were younger, older, never married, members of racial or ethnic minority groups, uninsured, and of moderate means. Structural, financial, and attitudinal barriers were frequent reasons for not obtaining care [18].

- Hurricane Katrina survivors with mental health disorders experienced unmet treatment needs, frequent disruptions of existing care, and widespread failure to initiate treatment for new-onset disorders. Future disaster management plans should anticipate both types of treatment needs [17].

\subsection{Capacity building}

Researchers have observed that whether or not the cause of a disaster is attributable to humans or to nature, the impact is a reflection of social forces (Calderon-Abbo [20]). To prepare for disasters, post-disaster planning and implementation require building and maintaining infrastructures and service networks that can support the delivery of services to everyone affected, but especially to people with special needs (e.g., children, frail older adults, people with cognitive disabilities, people who have mental or physical illnesses).

In consideration of the findings reviewed above, the scope of entities and actors involved in collaborations must be broadened and must encompass representatives from community institutions and care systems to ensure that outreach to special populations, and mental health assessments, are completed in a timely fashion after disaster strikes. In addition, a broad swath of community actors that represent local social service systems will help reduce the extensive under-treatment effects that Hurricane Katrina survivors report. Emergency planning needs to incorporate attention to ongoing and long-term recovery needs for disaster survivors that simultaneously builds and nourishes community resilience.

A well-coordinated public mental health response system requires joint planning and exercising with all possible partners. Public health, emergency management, law enforcement, and medical response teams are clearly central figures in planning and post-disaster intervention work, but lessons from Hurricane Katrina studies indicate that the addition of representatives from business communities, civic and faith-based organizations, advocacy organizations, schools, community-based clinics, and special needs facilities are needed to improve the breadth of effective behavioral health responses available.

While great strides have been made over the past few years with regard to increased collaboration and partnering across disciplines, much work remains to be done. The languages spoken across disciplines - disaster responders, public health, mental health, and others - vary widely. Priorities and ways of doing business in disaster vary as well, with disaster responders adhering to an incident command structure that is quite foreign to "civilian" responders, which includes most behavioral health responders. 
The level of integration between disaster behavioral health and emergency response varies considerably across states and territories. In some instances, disaster behavioral health responders can be found at the incident command center. In other instances, they are never called upon.

Few states have emotional support programs ready and able to address the myriad needs of people affected by disaster. Nationally there is not a credential or certification for individuals who would be called on to provide emotional support. Traumatized populations often suffer from many common attributes that render specialized psychological training critical, both interculturally and within a single society that shares common customs and outlooks. The inability to provide effective intervention to traumatized populations is likely the greatest psychological need in the world today. Danieli [21] and others have shown that the psychological effects of conflict are passed on through generations, from parent to child, making the effects of trauma more intractable. The literature on historic trauma helps us better understand the need for local, regional, and state support for those who have experienced a disaster or traumatic event. For children in particular, a community-wide trauma may leave a lasting impression. As the capacity for a child's mental concentration is diminished in response to the intrusion of traumatic memories or associated fears, so is the child's ability to play, and hence to learn and think creatively. Following a series of West Virginia floods that resulted in considerable destruction and some loss of life, teachers reported that children in their classrooms would begin to cry at the first sign of rain. Through an ongoing federal grant, teachers requested additional support from counselors with expertise in post-disaster behavioral health to address the children's emotional needs and assist them in coping with the traumatic memories (and for some, loss of home, possessions, or family). Support is occasionally available within existing community structures and by traditional means, but it is often the case that local mental health professionals have themselves been traumatized and suffered physically and psychologically, resulting in a diminished capacity to respond to the community needs.

\section{Conclusion: recommendations for disaster planning and response}

Knowledge from research regarding post disaster behavioral health and the need for psychological support can guide planners to support community resilience. It is essential that disaster managers and planners understand and plan for emotional upheaval of the community. Behavioral health responders need to recognize how and why post-disaster behavior influences the effectiveness of intervention. Education and communication are the medium for psychosocial interventions. To ensure psychosocial and behavioral health preparedness before disasters occur, disaster planners must engage community decision-makers in assessing longitudinal needs and help plan for the needs of a community in recovery. Keys to this include: 
- Assessing mental health symptoms. Planners must assess and determine the extent of use of alcohol and drugs, social support availability and needs, social service economic needs, and interagency information sharing that will facilitate sharing and stretching available resources, including staff.

- Community assessment. This would include measuring resilience and document the anticipated influences of significant psychological impacts on all residents and for special groups within the community.

- Identifying and applying brief psychological interventions to reduce traumatic stress reactions. Exposure and cognitive restructuring are the core elements of this intervention and have been shown to be effective in treating chronic PTSD (Foa and Rothbaum [22], Resick et al. [23]. The success of these treatments with both acute stress disorder and chronic PTSD suggests that it may be appropriate to deliver some aspects of these interventions to disaster survivors.

- Communicating known or possible limitations of identified interventions. The most powerful elements of the effective interventions are thought to involve exposure therapy and cognitive restructuring (a.k.a., cognitive therapy), and possibly anxiety management (including breathing retraining and relaxation). However, since it appears that adding anxiety management does not increase the effectiveness of an exposure/cognitive restructuring package (Bryant et al. [24]), this component should be studied as a stand-alone early intervention. Cognitive therapy is an intervention that may be relatively less emotionally provocative and may be more familiar to some clinicians. Disaster counselors often address negative cognitions, such as misinterpretations of acute stress reactions, guilt and shame, and negative beliefs about the future, albeit informally. Counselors should receive education about the role of cognition in development of PTSD (Ehlers and Clark [25]) and training in more systematic approaches to modification of distressing disaster-related beliefs.

- Screening for alcohol use. Identifying and applying brief alcohol use interventions. Research on brief alcohol interventions has shown that such services can lower alcohol consumption e.g., Heather [26]. Particularly relevant is a demonstration that a single session of counseling can reduce drinking in patients recently treated in hospital trauma centers (Gentilello et al. [27]).

- Identifying survivors at risk for long-term problems. One of the key functions of mental health workers is a referral of survivors for mental health treatment. Information from studies that document risk factors 
affecting development of PTSD and other negative sequelae in the contexts of disaster and traumatic stress will advance this objective (Brewin et al. [28], Norris et al. [1]). Additional training in risk factors and in use of screening instruments may help disaster workers better identify survivors who may benefit from referral to mental health services that are more intensive than brief education and support.

Current behavioral health responses to large-scale public health emergencies have not yet incorporated some of the important insights gleaned from U.S. terrorist attacks or Hurricane Katrina findings. Learning about the effect of psychological support on communities after recent tragic events will enhance the nation's ability to respond and recover from future events. Assessment of both individuals and community resilience is needed to plan specific, culturally appropriate interventions. Tools for assessment should be developed and tested. Screening for co-occurring mental, physical and drug/alcohol abuse will help to target appropriate interventions and referrals. Early screening may also identify those at risk for long term complications. An educated, skilled workforce is needed to provide behavioral health when a disaster occurs. It is important for planners to partner with key community organizations and to identify what each community needs in order to recover from a disaster.

\section{References}

[1] Norris, F., Friedman, M., Watson, P., Byrne, C., Diaz, E., and Kaniasty, K. (2002), 60,000 Disaster victims speak: part I. an empirical review of the empirical literature, 1981-2001 Psychiatry 65(3) Fall.

[2] Kaniasty, K., Norris, F., The experience of disaster: individuals and communities sharing trauma. In: Gist, R., Lubin, B., eds. Response to disaster: psychosocial, community, and ecological approaches. Philadelphia: Brunner/Mazel. 1999: pp. 25-62.

[3] Marmar CR, Weiss DS, Metzler TJ, Delucchi KL, Best SR, Wentworth KA. Longitudinal course and predictors of continuing distress following critical incident exposure in emergency services personnel. Journal of Nervous and Mental Disorders. 1999 Jan; 187(1): 15-22.

[4] Ruzek, J., Walser, R., Naugle, A., Litz, B., Mennin, D., Polusny, M., Ronell, D., Ruggiero, D., Yehuda, R., Scotti, J., (2008) Cognitivebehavioral psychology: implications for disaster and terrorism response; Prehospital and Disaster Medicine, http://pdm.medicine.wisc.edu .

[5] Shapiro, F. \& Maxfield, L. (2002). EMDR: Information processing in the treatment of trauma. In Session: Journal of Clinical Psychology, 58, 933946. Special Issue: Treatment of PTSD.

[6] Butler, A.S., Panzer, A.M., Goldfrank, L.R., Institute of Medicine Committee on Responding to the Psychological Consequences of Terrorism Board of on Neuroscience and Behavioral Health. (2003). Preparing for the psychological consequences of terrorism: A public health approach. Washington, D.C.: National Academies Press. 
[7] Koral, M., Green, B. L., and Gleser, G. C., 1999, Children's responses to a nuclear waste disaster: PTSD symptoms and outcome prediction, Journal of American Academy of Child and Adolescent Psychiatry, Vol. 38, No. 4,pp. 368-375.

[8] Institute of Medicine 2006.

[9] Schuster, M.A., Stein, B.D., Jaycox, L., Collins, R.L., Marshall, G.N., Elliott, M.N., et al. 2001. A national survey of stress reactions after the September 11, 2001, terrorist attacks N Engl J Med 345(20):1507-1512.

[10] North, C.S., McCutcheon V., Spitznagel E.L., and Smith, E.M. (2002). Three year follow-up of survivors of a mass shooting episode. Journal of Urban Health. 79(3):383-91.

[11] Schlenger, W.E., Caddell, J.M., Ebert, L., Jordan, B.K., Rourke, K.M., Wilson, D., et al. 2002. Psychological reactions to terrorist attacks: findings from the National Study of Americans' Reactions to September 11 JAMA 288(5):581-588.

[12] Silver, R.C., Holman, E.A., McIntosh, D.N., Poulin, M., Gil-Rivas, V., 2002. Nationwide longitudinal study of psychological responses to September 11 JAMA 288(10):1235-1244.

[13] Cardenas, J., Williams, K., Wilson, J. P., Fanouraki, G., \& Singh, A. (2003). PTSD, major depressive symptoms, and substance abuse following September 11, 22. 2001, in a midwestern university population. International Journal of Emergency Mental Health, 5(1), 15-28.

[14] Boscarino, J.A., Adams, R.E., Figley, C.R., Mental health service use after the world trade center disaster: utilization trends and comparative effectiveness Journal Nervous and Mental Dis. 2011 Feb; 199(2):91-9.

[15] Galea, S., Vlahov, D., Resnick, H., Ahern, J., Susser, E., Gold, J., et al. 2003. Trends of probable post-traumatic stress disorder in New York City after the September 11 terrorist attacks Am J Epidemiology 158(6):514524.

[16] Marshall, R., and Galea, S., Science for the Community: Assessing Mental Health After 9/11 J Clin Psychiatry 2004; 65[suppl 1]:37-43.

[17] Wang, P., Gruber, M., Powers, R., Schoenbaum, M., Speier, A., Wells, K., and Kessler, R.; Mental health service use among hurricane katrina survivors in the eight months after the disaster. Psychiatric Services 2007 58: 1403-1411.

[18] Kessler, R.C., Sonnega, A., Bromet, E., Hughes, M., Nelson, C.B. Posttraumatic stress disorder in the national comorbidity survey. Archives of General Psychiatry. 1995; 52:1048-1060.

[19] DeSalvo, K. B., Hyre, A. D., Ompad, D. C., Menke, A., Tynes, L. L., \& Muntner, P. (2007). Symptoms of posttraumatic stress disorder in a New Orleans workforce following Hurricane Katrina. Journal of Urban Health, $84,142-152$.

[20] Calderon-Abbo (2007) Psychiatry Services 58:1393, November 2007 doi: 10.1176/appi.ps.58.11.1393.

[21] Danieli, Y. (1985). The treatment and prevention of long-term effects and intergenerational transmission of victimization: A lesson from Holocaust 
survivors and their children. In C. R. Figley (Ed.), Trauma and its wake (pp. 295-313). New York: Brunner/Mazel.

[22] Foa, E.B. \& Rothbaum, B.O. (1998), Treating the Trauma of Rape: Cognitive Behavioural Therapy for PTSD, The Guilford Press, New York pp. 224-250.

[23] Resick, P.A., 2001. Stress and trauma. Philadelphia: Psychology Press. Pp.314-356.

[24] Bryant, R.A., Sackville, T., Dang, S.T., Moulds, M., Guthrie, R.: Treating acute stress disorder: an evaluation of cognitive behavior therapy and supportive counseling techniques. Am J Psychiatry 1999, 156:1780-1786.

[25] Ehlers A, Clark DM. A cognitive model of posttraumatic stress disorder. Behavior Research and Therapy. 2000 Apr; 38(4):319-45.

[26] Heather, N. (1996) The public health and brief interventions for alcohol consumption: the British experience. Addictive Behaviors, 21, 857-868.

[27] Gentilello, L.M., Rivara, F.P., Donovan, D.M., Jurkovich, G.J., Daranciang, E., Dunn, C.W., Villaveces, A., Copass, M., and Ries, R.R., Alcohol interventions in a trauma center as a means of reducing the risk of injury recurrence. Annals of Surgery, 230(4):473-483, 1999.

[28] Brewin CR, Andrews B, Valentine JD (2000) Meta-analysis of risk factors for posttraumatic stress disorder in trauma-exposed adults. J Consult Clin Psychol. 2000 Oct; 68(5):748-66.

[29] National Research Council (2006) Facing Hazards and Disasters: Understanding Human Dimension, National Academy Press; pp 71-123, ISBN-13: 978-0-309-10178-3 